VICKI GRIEVES

\section{opening the} dialogue for indigenous knowledges

developments in Australia

MARTIN NAKATA
$\begin{aligned} & \text { Disciplining the Savages, Savaging the } \\
& \text { Disciplines }\end{aligned}$
\begin{tabular}{|l} 
Aboriginal Studies Press, Canberra, 2007 \\
ISBN 9780855755485 \\
RRP $\$ 44.95$
\end{tabular}

This book represents an important statement of academic achievement by a Torres Strait Islander, one who has navigated through the demands of Western education and notably the first who has achieved a university doctorate. Nakata is thus well placed to critique Western knowledge acquisition and its impacts on 'Islander' peoples. He importantly approaches a history of Islander contact with the Western colonialist institution of anthropology that originally defined Islanders as a people without historical agency. Other reviewers, including Beckett and Rowse provide a comprehensive account and critique of the contents of this book: Nakata's exposition of his experience as an Islander child and adolescent in the Western education system, his critical readings of early travellers' and ethnographers' reports of the perceived 'pre-historical' savagery of Islanders, his take on the relationship between Western and Indigenous knowledge systems and finally the key concepts of an Indigenous standpoint and the cultural interface that promise to show a way forward. ${ }^{1}$ This review will be confined to a discussion of these latter concepts reflecting my research interests in Indigenous knowledges development in Australia.

Martin Nakata purports to provide a foundation for Indigenous knowledges development in Australia with this book and it is certainly being received in this way. ${ }^{2}$ Concentrating on the second section, wherein Nakata moves from his personal experiences in Indigenous education to develop a theoretical approach to Indigenous knowledges development, my reading only reinforces the argument against a homogenising of Indigenous peoples 
such as occurs in postcolonial approaches and which has been critiqued by various scholars. ${ }^{3}$ The centrality of philosophical, cultural and historical divergences that produce the autonomy of Indigenous groups cannot be em- the phasised enough. In the modern nation state of Australia are the distinct Torres Strait Islander peoples, 'Islanders', comprised of various groups with a common cultural heritage, along with the diverse peoples of the mainland who have come to be called 'Aboriginal' within a settler colonial regime. Mainland peoples, also glossed as 'Indigenous' (along with Islanders and other migrant groups, a source of potential confusions), in fact comprise a plethora of variant groups over an immense geography, distinct from each other but with a common cultural heritage. This cultural base is itself clearly distinct from that of the people of the Torres Strait Islands.

Indigenous knowledge development is foremost concerned with the connections between Indigenous peoples' philosophies and the derived ontologies and epistemologies that provide a way of understanding what it means to be an Indigenous person. Thus the Indigenous researcher is informed by those experiences, knowledges and beliefs about the world that inform their distinct experiences of being and thus wellbeing, making research outcomes meaningful in Indigenous terms. ${ }^{4}$ Nakata's adoption of the standpoint theory is by contrast individualist, from within Western epistemologies, when the essence of being Aboriginal lies in kinship and connectedness. The principles that bind diverse Aboriginal peoples across Australia in the one cultural tradition are derived from connectedness, also referred to as relatedness, exemplified in the concept of 'pattern thinking' explained by David Mowaljarlai, senior lawman of the Ngarynin people of the west Kimberley. He said:

We are really sorry for you people. We cry for you because you haven't got meaning of culture in this country. We have a gift we want to give you. We keep getting blocked from giving you that gift. We get blocked by politics and politicians. We get blocked by media, by process of law. All we want to do is come out from under all of this and give you this gift. And it's the gift of pattern thinking. It's the culture which is the blood of this country, of Aboriginal groups, of the ecology, of the land itself. ${ }^{5}$

This is the concept of the connectedness of all of creation, animate and inanimate, that is the basic tenet of Aboriginal philosophy, and to illustrate this Mowaljarlai drew a pattern of lines across the whole of a map of Australia. These connections are more than one- or twodimensional and they incorporate timeframes to the extent that the 'Dreaming' is ever present, 'everywhen'. For Aboriginal people, each of the lines represents the law or knowledge that prescribes these connections and provides the blueprint for ensuring that they continue.

While the concept of the cultural interface utilised by Nakata similarly privileges a particular notion of connectedness, rather than oppositional constructs, it is essentially different from Aboriginal understandings of cultural and thus colonial relationships. Nakata 
characterises the cultural interface as existing relationship with their homeland is necessarily in a postcolonial space. While he does not imaginative' ${ }^{6}$ This is not to question the explicitly recognise this in his work, it is evi- authenticity of this identity but is rather a quesdent from his description of the cultural inter- tioning of how much this relies on connections face as a place of essentially equal human, and to land and the natural world and how diveroverwhelmingly individual, interaction. (199- gent such an identity is from the lived, prac200) This conceptual tool has parallels with the tical, day-to-day experience of being a person historical notion of the frontier, the frontier surrounded by kin and whose life is driven by being a space where notionally competing the imperative of connectedness, obligation cultures, epistemologies and ontologies are and reciprocity.

brought together within the colonial project, Further, while Nakata makes much of 'deciinteracting, reacting, providing agency and sions' made at the interface he does not seem to choice, developing new and 'hybrid' ways of be cognisant of the reality that these are proceeding. The notion of an ongoing and restrained by social, economic and political shifting frontier as a continuing space of oppor- factors. These decisions alone do not produce tunity for Indigenous people living within a the desired outcomes for the individual, colonial regime is attractive in many ways as a whether one accepts ongoing colonisation and means of positioning research. settler colonial hegemony operating within

However, the cultural interface is funda- Indigenous Australians' lives, or not. mentally problematic as a means of positioning It is understandable that Torres Strait Aboriginal Indigenous knowledges research. Islanders do not see themselves as a colonised It opens up the possibility of postcolonial people in the way that many Indigenous groups approaches that have been overwhelmingly on the Australian mainland do. For example, rejected by Aboriginal scholars who recognise they celebrate their adoption of Christianity colonialism as ongoing, not in the past, and as the Coming of the Light in regular, public also for the reasons reflected in the work of ceremony; they do stand in a very particular Thomas referenced earlier. Homogenising of relationship to the Australian nation state, colonial experiences or of Indigenous cultures having made a conscious decision to join the cannot bear the scrutiny of scholarship that Australian polity when Papua New Guinea uncovers dynamic complexities over time. The gained independence from the Australian employ of the (postcolonial) imaginary in ident- government as a newly independent Indiity and scholarship can lead to greater homo- genous state. Their history is that of island, genisation, development of stereotypes, or at maritime people, co-opted into exploitative least positions that are not rooted in empirical labour relations and economic incursions into research. As Rowse points out, the majority of their maritime resource base, but not facing Islanders have left their homelands-Nakata's widespread colonial dispossession from their ancestral Naghir Island is deserte-and 'their lands as mainland Aboriginal people have. One 
can imagine situations that have led to a great deal of choice, and therefore decisions, about Islanders' interaction with the colonial state: the generations of maritime visitors from other social, political and cultural contexts, a passing parade of choices that have led to a willingness to engage with the 'outsiders' on many levels and which have led them into their own particular relationship with the Australian settler colonial state.

While seemingly not cognisant of ongoing colonial dispossession, Nakata's model seems also to be based on a wide-eyed approach to Western education and academic process. While education per se is beneficial, he seems to subscribe to a notion of equality and objectivity in academic processes, unsullied by power plays and indeed hegemonic processes that preserve the status quo. While overt opposition to Indigenous peoples is easily apprehended and able to be addressed through intellectual engagement, perhaps the greatest threat to Indigenous knowledge development is more seductive and covert. Indigenous knowledges, in this country at least, are developing from within Western sites of knowledge production and danger lies in this academic endeavour becoming too acceptable, commodified, packaged for Western consumption and along the way losing its critical dimension. Perhaps the most important value in Indigenous knowledges is that Indigenous peoples stand in a very particular relationship to the Western knowledges that have been used to oppress them. This does not imply that Indigenous knowledge is necessarily antagonistic to Western epis- temologies, only that it stands in a particular relationship of critical dialogue with the knowledge systems recognised by the dominant society within which Indigenous peoples find themselves.

In contrast, Nakata describes his Indigenous standpoint theory as having developed out of the cultural interface as a 'distinct form of analysis ... itself both a discursive and an intellectual device to persuade others and elevate what might not have been a focus of attention by others'. (214) This theory, derivative of feminist theoretical approaches, does not incorporate ways in which the Indigenous 'other' can escape from the colonial hegemony of definition, theory, appropriation and relegation to the margins, except by persuasion. Even if persuasion is possible, we need to know what the alternative is-what is it that we are escaping (the entanglement of a very contested knowledge space at the cultural interface) to? Where at least are the philosophical values for the present and future? Nakata does not provide an answer to this; his work seems to be underpinned by a faith in education and progress and the moral, ethical and theoretical basis of decisions made at the interface don't seem to matter. What are missing are the cultural values as derived from Indigenous philosophy. Elsewhere Nakata seemingly defines Indigenous knowledges narrowly as those already being appropriated in the Western academy across diverse disciplines, and he relinquishes the opportunity to argue for the development of Indigenous knowledges as a discipline in its own right (182-92), as is happening in 
many parts of the world, including within Australia.

And the baseline for such developments? In Australia, Aboriginal philosophy, espousing the connectedness of all things, exemplified by the 'pattern thinking' of Mowaljarlai and the associated need for opposition to the 'colonial dome of thinking' iterated by Plangermairreenner Jim Everett, for example, promises to bring order to the entanglement, potential anarchy and chaos of the 'cultural interface' with the potential to take us safely into a 'reconciled' or 'decolonised' future.

VICKI GRIEVES is Worimi from the mid north coast of New South Wales and a historian. Her completed PhD thesis, Approaching Aboriginal History: Family, Wellbeing and Identity in Aboriginal Australia, presents a case for a new Australian historiography based on Indigenous knowledges approaches and explores mixed-race marriages in Worimi from this theoretical base.

1. Jeremy Beckett, 'Disciplining the Savages: Savaging the Disciplines', Australian Journal Of Anthropology, vol. 19, no. 3, 2008; Tim Rowse, 'Review of Martin Nakata's Disciplining the Savages: Savaging the Disciplines', History Australia, vol. 5, no. 2, Monash University Press, Melbourne, 2008.

2. Shino Konishi, 'Review of Disciplining the Savages: Savaging the Disciplines', Journal of Australian Studies, vol. 32, no. 2, June 2008, p. 286. I also refer to the seminar Martin Nakata presented at the Macquarie University as part of the Wara Wara seminar series in 2008.

3. I refer for example to Nicholas Thomas, Colonialism's Culture: Anthropology, Travel and Government, Princeton University Press, New Jersey, 1994, pp. $39-59$.
4. Linda Tuhiwai Smith, Decolonising Methodologies: Research and Indigenous Peoples, Zed Books, London, 1999

5. ABC Radio, The Law Report: Aboriginal Law (David Mowaljarlai), 1995, transcript at <http://www.abc net.au/rn/talks/8.30/lawrpt/lstories/lr311001.htm> See also Vicki Grieves 'Aboriginal Spirituality: A Baseline for Indigenous Knowledges Development in Australia', Canadian Journal of Native Studies, vol. 28, no. 2, 2008, pp. 361-96.

6. Rowse, p. 61. 